\title{
Erratum to: Evidence of light-induced phenotypic plasticity in zoanthids: editorial comment on the feature article by Ong et al.
}

\section{Ross Hill}

Published online: 22 January 2014

(C) Springer-Verlag Berlin Heidelberg 2014

Erratum to: Mar Biol (2013) 160:1051

DOI 10.1007/s00227-013-2225-5

Unfortunately, in the print and online version of article, the title was published incorrectly. The correct title should read as "Evidence of light-induced phenotypic plasticity in zoanthids: editorial comment on the feature article by Ong et al."

Furthermore, the citation Wei et al. (2013) should be replaced with Ong et al. (2013) while the reference Wei ON, Reimer JD, Todd PA (2013) should be replaced with the following Reference section.

\section{Reference}

Ong CW, Reimer JD, Todd PA (2013) Morphologically plastic responses to shading in the zoanthids Zoanthus sansibaricus and Palythoa tuberculosa. Mar Biol. doi:10.1007/s00227-012-2158-4

The online version of the original article can be found under doi:10.1007/s00227-013-2225-5.

R. Hill $(\bowtie)$

Centre for Marine Bio-Innovation and Sydney Institute

of Marine Science, School of Biological,

Earth and Environmental Sciences,

The University of New South Wales,

Sydney, NSW 2052, Australia

e-mail: Ross.Hill@unsw.edu.au 